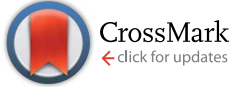

Cite this: RSC Adv., 2017, 7, 13398

\title{
Immobilization of selenite from aqueous solution by structural ferrous hydroxide complexes $\uparrow$
}

\begin{abstract}
Yong Zhang, ${ }^{\text {ab }}$ Mao Fu, ${ }^{\text {b }}$ Deli Wu${ }^{\star a}$ and Yalei Zhang ${ }^{\star a}$
Ferrous hydroxyl complexes (FHCS) were synthesized by precipitation from Fe(॥) sulfate salts with sodium hydroxide in an anoxic atmosphere. Effects of the $[\mathrm{Fe}(॥)] /\left[\mathrm{OH}^{-}\right]$ratio, dosage and sequential extraction scheme were elaborated on selenium (Se)(Iv) removal by FHCs. Se(IV) removal by FHCs was more coincident with the pseudo-second order kinetic model. The BET isotherm was the best fit model for the data of equilibrium experiments and $R^{2}$ was 0.9902. Se(Iv) removal by FHCs changed with various $\left[\mathrm{Fe}\left({ }_{\mathrm{I}}\right)\right] /\left[\mathrm{OH}^{-}\right]$ratios, and the maximum removal capacity was $256.41 \mathrm{mg} \mathrm{g}^{-1}$ by $\mathrm{FHC}\left([\mathrm{Fe}(॥)] /\left[\mathrm{OH}^{-}\right]=\right.$ 1:2). X-ray photoelectron spectroscopy results indicated the mechanism of Se(IV) removal by $\mathrm{FHC}\left([\mathrm{Fe}(॥)] /\left[\mathrm{OH}^{-}\right]=1: 1\right)$ to be a combination of adsorption and reduction, whereas reduction was the primary mechanism for Se(Iv) removal by $\mathrm{FHC}\left([\mathrm{Fe}(॥)] /\left[\mathrm{OH}^{-}\right]=1: 4\right)$. A sequential extraction scheme was employed to study Se speciation before and after the reaction. Se species were classified into five groups (water-soluble, exchangeable, elemental Se, oxide-containing iron state, selenide). Results indicated that elemental Se was the primary species in the reaction products.
\end{abstract}

Received 3rd November 2016 Accepted 9th January 2017

DOI: $10.1039 / c 6 r a 26225 b$

www.rsc.org/advances state of $\mathrm{Se}(-\mathrm{II})$ is $\mathrm{HSe}^{-}$, and $\mathrm{H}_{2} \mathrm{Se}(\mathrm{aq})$ is the main form $(\mathrm{pH}<4)$. As reported by the Environmental Protection Agency (FRL-56497), the acute toxicity of Se(Iv) is nearly tenfold higher than that of $\mathrm{Se}(\mathrm{vI})$ when they simultaneously coexist in surface water with the same concentration in the presence of oxygen. ${ }^{9}$

The chemical properties of Se solutions are considerably unique, with extremely strong mobility that is not influenced by solubility, and poor absorption by clay or granite. Therefore, reduction from high valence $\mathrm{Se}(\mathrm{Iv})$ to $\mathrm{Se}(0)$ deposited into sediment is the primary reason for the hindrance of Se mobility. $\mathrm{Fe}(\mathrm{II})$-mineral is a type of ubiquitous mineral that is reducible in nature, but there are others, including magnetite, iron pyrite, pyrrhotite and siderite. Retardation of selenite reduction by $\mathrm{Fe}(\mathrm{II})$-mineral has aroused extensive concern. ${ }^{2,9-13}$ Studies have shown that zero-valent iron and nano zero-valent iron ${ }^{\mathbf{1 4 , 1 5}}$ exhibit a low removal rate on Se because dense iron oxides can form on the surface and lead to low reaction activity. However, ferrous hydroxyl complexes (FHCs) can achieve good performance in this respect. For example, reductive transformation of reactive black 5 by FHCs has shown that the latter can reduce azo dyes by cleavage of chemical bonds and generate aniline. ${ }^{\mathbf{1 6}}$ Owing to the low removal efficiency, it is hard to introduce these natural $\mathrm{Fe}(\mathrm{II})$-minerals into environmental engineering. It is well-known that Se(Iv) in the environment is absorbed on the surface of zero-valent iron with chemisorption, and is gradually reduced to $\mathrm{Se}(0), \mathrm{Se}(-\mathrm{I})$ or $\mathrm{Se}(-\mathrm{II})$. A similar reduction mechanism has been mentioned by immobilization of selenite on $\mathrm{Fe}_{3} \mathrm{O}_{4}$ and $\mathrm{Fe} / \mathrm{Fe}_{3} \mathrm{C}$ ultra-small particles. ${ }^{9,17}$ The mechanism of Fe-Mn hydrate application on Se(Iv) involves loading of Se(Iv) onto the active site of the amorphous form of $\mathrm{Fe}(\mathrm{III})-\mathrm{Mn}$ (III)
${ }^{a}$ State Key Laboratory of Pollution Control and Resource Reuse, College of Environmental Science and Engineering, Tongji University, Shanghai, 200092, P. R. China.E-mail: zhangyalei@tongji.edu.cn

${ }^{b}$ Key Laboratory for Information System of Mountainous Areas and Protection of Ecological Environment, Guizhou Normal University, 116 Baoshan North Rd, Guiyang, Guizhou, 550001, P. R. China

$\dagger$ Electronic supplementary information (ESI) available. See DOI: 10.1039/c6ra26225b 
hydrate, which forms an inner-orbital coordination compound (bidentate binuclear). Meanwhile, the active sites on the surface of $\mathrm{Fe}(\mathrm{III})-\mathrm{Mn}$ (III) hydrate increase with decreasing $\mathrm{pH}$ value. ${ }^{18}$ The green rusts (GRs) formed in the reaction system of $\mathrm{OH}^{-}$and $\mathrm{Fe}(\mathrm{II})$ or $\mathrm{Fe}(\mathrm{III})$ belong to layered double hydroxides (LDHs). Myneni et al. ${ }^{19}$ studied the reducing effect of GRs on selenite and estimated that $\mathrm{GR}\left(\mathrm{SO}_{4}{ }^{2-}\right)$ could reduce selenate to selenite with $\mathrm{Se}(0)$ and a small amount of $\mathrm{Se}(-\mathrm{II})$. The mechanism was found to involve physical absorption (ion exchange and ion coexistence) due to the LDH structure of GR. Meanwhile, chemisorptions of $\mathrm{Se}(\mathrm{IV})$ and bidentate binuclear iron polyhedrons occur in the $\mathrm{pH}$ range 7.0-9.3, which is accompanied by the production of $\mathrm{Se}(0)$ and $\mathrm{FeSe}_{x}$ without $\mathrm{Fe}_{2}\left(\mathrm{SeO}_{3}\right)_{3}$.

FHCs in the presence of a structural Fe(II) complex possess high reduction activation. Wu et al. ${ }^{\mathbf{1 6 , 2 0}}$ evaluated the disposal of organic pollutants by structural Fe(II). They also discovered that structural Fe(II) had better removal efficiency at lower cost than GRs or siderite. ${ }^{21}$ However, few studies have focused on $\mathrm{Se}(\mathrm{vI})$ removal by structural $\mathrm{Fe}(\mathrm{II})$ from aqueous solution, and the mechanism for the removal of Se(Iv) by structural Fe(II) has not been studied. Therefore, the objectives of this study were to: (1) investigate the removal efficiency of Se(Iv) with various dosages of structural $\mathrm{Fe}(\mathrm{II})$ and reaction kinetics, (2) explore the effect of various $\left([\mathrm{Fe}(\mathrm{II})] /\left[\mathrm{OH}^{-}\right]\right.$) ratios by structural $\mathrm{Fe}(\mathrm{II})$ on removal of $\mathrm{Se}(\mathrm{Iv})$, and (3) clarify the envelopes of Se(Iv) reduction removal by structural Fe(II).

\section{Materials and methods}

\subsection{Materials}

All reagents were of analytical grade and were used without further purification. Ultrapure water $\left(18.2 \mathrm{M} \Omega \mathrm{cm}^{-1}\right.$, Millipore, USA) was used for all experiments. The water was deoxygenated by purging with high-purity nitrogen for $>30 \mathrm{~min}$. Se(Iv) stock solution was prepared with $\mathrm{K}_{2} \mathrm{SeO}_{3}$ in an amber bottle with deoxygenated ultrapure water.

Structural $\mathrm{Fe}$ (II) was synthesized by precipitation from $\mathrm{Fe}(\mathrm{II})$ sulfate salts with sodium hydroxide $(\mathrm{NaOH})$. Briefly, $\mathrm{FeSO}_{4}$ $\cdot 7 \mathrm{H}_{2} \mathrm{O}(0.1 \mathrm{M})$ was dissolved in $80 \mathrm{~mL}$ deoxygenated ultrapure water in a $100 \mathrm{~mL}$ flask under magnetic stirring. Then, $100 \mathrm{~mL}$ of $\mathrm{NaOH}(2.5 \mathrm{M})$ solution, corresponding to $[\mathrm{Fe}(\mathrm{II})] /\left[\mathrm{OH}^{-}\right]$ratios of $2: 1,1: 1,1: 2,1: 3$, and $1: 4$, respectively, was added to the solution under the same magnetic-stirring and anaerobic conditions. Finally, structural Fe(II) was generated, with ratios referred to as $\operatorname{FHC}(2: 1), \operatorname{FHC}(1: 1), \operatorname{FHC}(1: 2), \operatorname{FHC}(1: 3)$, and $\mathrm{FHC}(1: 4)$. All preparation work was performed in an anoxic atmosphere. Note that structural Fe(II) was freshly prepared to avoid possible oxidation.

\subsection{Batch experiments on selenite removal and equilibrium}

Adsorption kinetics experiments were performed in glass bottles $(100 \mathrm{~mL})$ containing $80 \mathrm{~mL}$ of selenite solution $(30.0 \mathrm{mg}$ $\left.\mathrm{L}^{-1}\right)$ with specific levels of adsorbent $\left(228.0 \mathrm{mg} \mathrm{L}^{-1}\right)$. Individual bottles were sacrificed after specific time intervals $(5,10,20,30$, and $60 \mathrm{~min}$ ) and immediately filtered using a $0.45 \mu \mathrm{m}$ membrane.
For the sake of simplicity of computation, equilibrium experiments were performed by adding $200.0 \mathrm{mg} \mathrm{L}^{-1}$ adsorbent into a series of $100 \mathrm{~mL}$ bottles filled with $80 \mathrm{~mL}$ selenite solutions at different concentrations (20.0, 40.0, 50.0, 70.0, 100.0 and $150.0 \mathrm{mg} \mathrm{L}^{-1}$ ); bottles were sealed and magnetically stirred at room temperature under the protection of a $\mathrm{N}_{2}$ atmosphere for $1 \mathrm{~h}$ to ensure equilibrium.

\subsection{Sequential extractions}

Se speciation, from reacting various $[\mathrm{Fe}(\mathrm{II})] /\left[\mathrm{OH}^{-}\right]$ratios with Se(Iv) sediments, was determined by a sequential extraction scheme according to previously published methods. ${ }^{22,23}$ A fivestage sequential extraction procedure was used in sediment with the following extraction: (1) water-soluble Se (ultrapure water); (2) exchangeable Se (0.1 M NaH$\left.{ }_{2} \mathrm{PO}_{4}, \mathrm{pH}=7\right)$; (3) elemental state Se $\left(1.0 \mathrm{M} \mathrm{Na}_{2} \mathrm{SO}_{3}, \mathrm{pH}=7\right)$, water bath ultrasonication for $3 \mathrm{~min}$; (4) oxide-containing Fe state $\left(15 \% \mathrm{CH}_{3}\right.$ $\mathrm{COOH}$ and digestion); ${ }^{24}$ (5) Se compound states (selenide) (0.5 g $\mathrm{KClO}_{3}$, concentrated hydrochloric acid). Extractions were performed in $50 \mathrm{~mL}$ Falcon tubes, and each extraction step used 20 $\mathrm{mL}$ of extractant, with shaking or ultrasound, centrifugation (3500 rpm) for $15 \mathrm{~min}$ and filtration.

\subsection{Analytical methods and characterization}

Aqueous Se(Iv) concentration was determined using ICP (720ES; Agilent, USA). $\mathrm{pH}$ was measured using pHSJ-3F (Shanghai Precision and Scientific Instruments, China). After filtration, solid products were rinsed with ultrapure water and immediately freeze-dried. Morphology of structural Fe(II) solid phase was obtained using a field emission scanning electron microscope (S-4800; Hitachi, Japan) equipped with an energy dispersive X-ray spectrometer at $200 \mathrm{kV}$. XRD patterns were collected using a D8 Advance Powder X-ray diffractometer (Bruker, USA) and a $\mathrm{Cu} \mathrm{Ka}(\lambda=1.5406 \AA)$ radiation source (40 $\mathrm{kV}, 40 \mathrm{~mA})$; the diffraction angle $(2 \theta)$ was recorded from $10^{\circ}$ to $80^{\circ}$ with a scanning speed of $1^{\circ} \min ^{-1}$ and a step size of $0.02^{\circ}$. Related oxidation states on the surface of Fe(III)-contained solid products were analyzed by X-ray photoelectron spectroscopy (XPS) using a PHI-5000 Versaprobe spectrometer equipped with a rotating $\mathrm{Al}$ anode generating $\mathrm{Al} \mathrm{K} \alpha \mathrm{X}$-ray radiation at $1486.6 \mathrm{eV}$.

\section{Results and discussion}

\subsection{Batch experiments on selenite removal and equilibrium}

Selenite removal studies have important roles in adsorption studies because they can predict the equilibrium time and removal rate of selenite from aqueous solution. Fig. 1 presents the selenite removal in aqueous solution as a function of contact time. With an initial selenite solution at $30 \mathrm{mg} \mathrm{L}^{-1}$, the selenite removal efficiency was $>99 \%$ within $30 \mathrm{~min}$ and remained constant over $60 \mathrm{~min}$, which is in agreement with the study published by Myneni et al., who used $\mathrm{Fe}(\mathrm{II}) / \mathrm{Fe}(\mathrm{III})$ oxide (GRs) to remove selenite. ${ }^{19}$ The aqueous Se(Iv) concentration dropped quickly, $>48 \%$ in the first $0.01 \mathrm{~h}$ (36 s). As reported by Han et al., Se(Iv) can be completely removed by FeS $\left(1.0 \mathrm{~g} \mathrm{~L}^{-1}\right)$ 
within 30 min. ${ }^{25}$ During the course of the experiment, the milky white suspension gradually became atrovirens and, $1 \mathrm{~h}$ later, reddish-brown substances formed. A possible explanation for this phenomenon can be that structural Fe(II) was oxidized to $\mathrm{Fe}(\mathrm{II}) / \mathrm{Fe}$ (III) and/or Fe(III) hydroxides in the reaction. Another possibility is that the red $\mathrm{Se}(0)$ formed, which was also observed by Breynaert et al. in which red $\mathrm{Se}(0)$ particles formed on the FeSe surface after FeS reacted with $\mathrm{Se}(\mathrm{Iv})$ for 3 days. ${ }^{2} \mathrm{Se}(\mathrm{Iv})$ removal by structural Fe(II) hydroxides could be described by a generalized pseudo-first order kinetic model and generalized pseudo-second order kinetic model. Meanwhile, the correlation coefficient $\left(R^{2}\right)$ of the generalized pseudo-first order kinetic model was 0.8505 , whereas the generalized pseudo-second order kinetic model was 0.9828 (Fig. 1 inset). Se(Iv) removal by structural $\mathrm{Fe}(\mathrm{II})$ was more coincident with the pseudo-second order kinetic model. In the following section, the generalized pseudo-second order kinetic model was further studied, with an expression shown as eqn (1) and the corresponding half-life $\left(t_{1 /}\right.$ 2) could be calculated using eqn (2).

$$
\begin{gathered}
r=\frac{\mathrm{d}[\mathrm{Se}(\mathrm{IV})]}{\mathrm{d} t}=k\left(q_{\mathrm{e}}-q_{t}\right)^{2} \\
t_{1 / 2}=\frac{1}{k C_{0}}
\end{gathered}
$$

where $[\mathrm{Se}(\mathrm{Iv})]$ shows $\mathrm{Se}(\mathrm{Iv})$ concentration $\left(\mathrm{mg} \mathrm{\textrm {L } ^ { - 1 } )}\right.$ at time $t$ (min), $k$ is the pseudo-second-order reaction rate constant and $t_{1 / 2}$ stands for the half-life of Se(Iv) removal. Calculation revealed the reaction rate constant $(k)$ and $t_{1 / 2}$ to be $1.05 \times 10^{-3} \mathrm{mg} \mathrm{g}^{-1}$ $\min ^{-1}$ and 31.7 , respectively.

Fig. 2 shows the selenite removal rate and adsorption capacity equilibrium concentration. The results were fitted with the Langmuir model (3), Freundlich model (4) and BET isotherm (5), respectively:

$$
\frac{C_{\mathrm{e}}}{q_{\mathrm{e}}}=\frac{C_{\mathrm{e}}}{q_{\max }}+\frac{1}{K_{\mathrm{L}} q_{\max }} \frac{C_{\mathrm{e}}}{q_{\mathrm{e}}}
$$

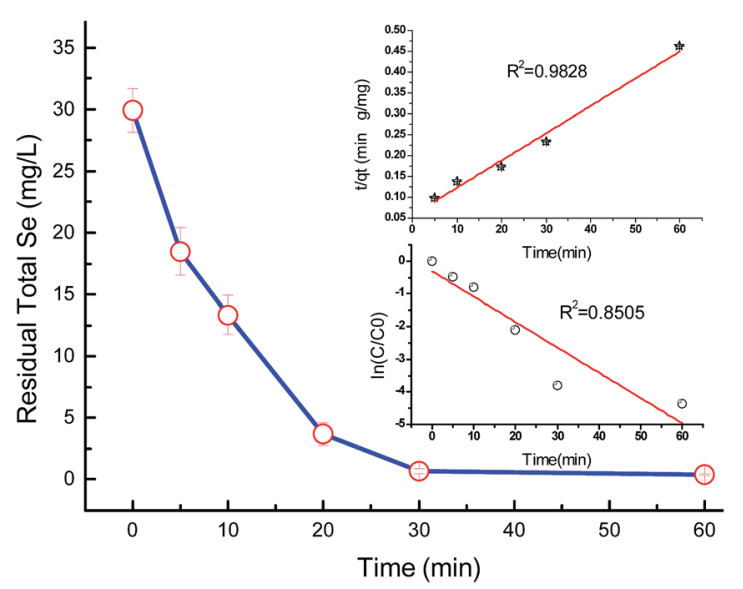

Fig. 1 Adsorption kinetics of Se(Iv). Error bars represent standard error of the mean. Initial $[\mathrm{Se}(\mathrm{IV})]=30.0 \mathrm{mg} \mathrm{L}^{-1}$ and $\mathrm{FHC}(1: 2)$ dosage $=$ $228.0 \mathrm{mg} \mathrm{L}^{-1}$.

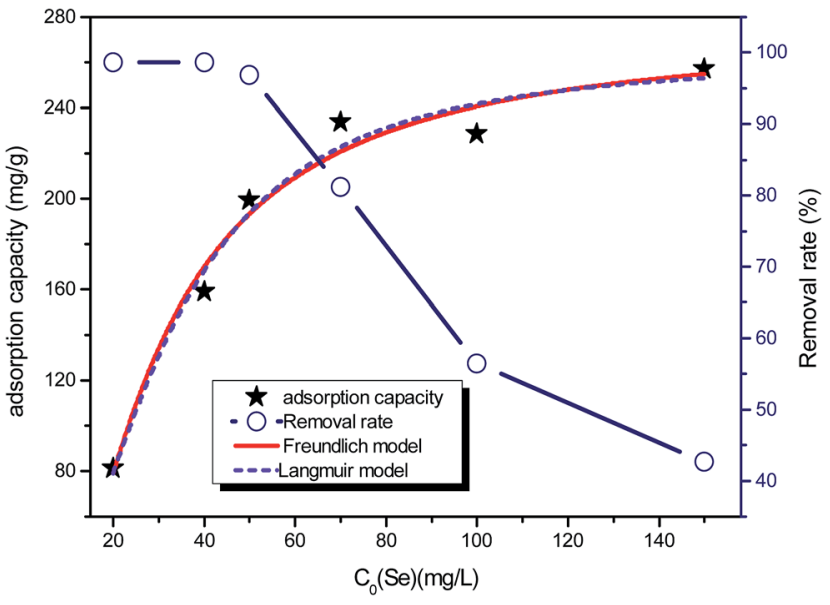

Fig. 2 Se(Iv) removal $\left(\mathrm{mg} \mathrm{g}^{-1}\right)$ capacity and percentage removal rate. $\mathrm{FHC}(1: 2)$ dosage $=200.0 \mathrm{mg} \mathrm{L} \mathrm{L}^{-1}$, initial [Se(Iv)] concentrations = $\left(20.0,40.0,50.0,70.0,100.0\right.$ and $\left.150.0 \mathrm{mg} \mathrm{L}^{-1}\right)$, and reaction time $=$ $1 \mathrm{~h}$.

$$
\begin{gathered}
\ln q_{\mathrm{e}}=\ln K_{\mathrm{F}}+\frac{1}{n \ln C_{\mathrm{e}}} \\
\frac{C_{\mathrm{e}}}{q_{\mathrm{e}}\left(C_{0}-C_{\mathrm{e}}\right)}=\frac{1}{q_{\max } C}+\frac{C-1}{q_{\max } C} \frac{C_{\mathrm{e}}}{C_{0}}
\end{gathered}
$$

where $C_{\mathrm{e}}$ is the equilibrium concentration of selenite $\left(\mathrm{mg} \mathrm{L}^{-1}\right), C_{0}$ is the assumed initial se concentration, $q_{\mathrm{e}}$ is the equilibrium adsorption capacity $\left(\mathrm{mg} \mathrm{g}^{-1}\right), q_{\max }$ is the maximum adsorption capacity $\left(\mathrm{mg} \mathrm{g}^{-1}\right), K_{\mathrm{L}}$ is the adsorption constant $\left(\mathrm{L} \mathrm{mg}^{-1}\right)$, and $K_{\mathrm{F}}$ and $1 / n$ are Freundlich isotherm constants related to adsorption capacity and intensity of adsorption, respectively. Models (BET, Langmuir, Freundlich) were fitted to data, and the values of model parameters are summarized in Table 1. The BET isotherm was the best-fit model, whose $R^{2}$ was 0.9902 , whereas there was little difference between the Freundlich isotherm $\left(R^{2}=0.9609\right)$ and Langmuir isotherm $\left(R^{2}=0.9650\right)$. Se(Iv) removal was well described by the BET isotherm, so it can be inferred that selenite primarily experienced adsorption on the surface of structural Fe(II). Afterwards, Se(Iv) could be reduced to $\mathrm{Se}(0), \mathrm{Se}(-\mathrm{II})$ and precipitated as FeSe or $\mathrm{FeSe}_{x}$. The maximum adsorption capacity was $256.41 \mathrm{mg} \mathrm{g}^{-1}$, suggesting that structural Fe(II) was more potential and effective than other related adsorbents. ${ }^{25-28}$

Although the BET model was developed to describe multilayer gas sorption, it could also represent continuous accumulation of adsorbates on the solid surface until a maximum level of sorption. The BET model was preferable for use over a solid solution system because of its simplicity and ability to ascertain if continuous adsorption (e.g., polymeric cluster and surface precipitates) occurs. The constant $K_{\mathrm{F}}$ of the Freundlich model was defined as adsorption capacity, ${ }^{29}$ and the unit equilibrium concentration of structural $\mathrm{Fe}(\mathrm{II})$ for selenite removal was 144.89, which was higher than that for nZVI. ${ }^{30}$ Moreover, the value $1 / n$ in the Freundlich model for selenite was $>1$, suggesting that this isotherm was nonlinear, which can be attributed to adsorption-site heterogeneity, electrostatic attraction and other sorbent-sorbate interactions. Fig. 2 shows that the selenite 
Table 1 Summary of model parameters for Se(IV) removal by structural Fe(॥)

\begin{tabular}{|c|c|c|c|c|c|c|}
\hline \multicolumn{3}{|c|}{ Langmuir isotherm } & \multicolumn{3}{|c|}{ Freundlich isotherm } & $\frac{\text { BET isotherm }}{R^{2}}$ \\
\hline
\end{tabular}

removal rate and adsorption capacity had a significant negative correlation. Chemical precipitation may have an important role at a higher initial selenite concentration; therefore, the seleniteremoval mechanism at high initial selenite concentrations (100-1000 $\mathrm{mg} \mathrm{L}^{-1}$ ) may include adsorption and co-precipitation processes. However, Chubar et al. reported that surface precipitation was not part of the processes at the interface between $\mathrm{Fe}-\mathrm{Mn}$ mixed adsorbent and aqueous selenite. ${ }^{31}$ Therefore, the mechanism of selenite removal by structural $\mathrm{Fe}(\mathrm{II})$ required further study, as shown in subsequent sections.

\subsection{Effect of FHC dosage}

As shown in Fig. 3, the residual concentration of Se(Iv) continuously decreased with increasing $\operatorname{FHC}(1: 2)$ dosage. When the dosage was $>56.0 \mathrm{mg} \mathrm{L}^{-1}$, the removal rate slowed and residual concentration of $\mathrm{Se}(\mathrm{Iv})$ was $4.70 \mathrm{mg} \mathrm{L}^{-1}$. After a $1 \mathrm{~h}$ reaction, when the dosage of $\mathrm{FHC}(1: 2)$ was $35.0 \mathrm{mg} \mathrm{L}^{-1}$, the removal rate of Se(Iv) was $51.7 \%$. When the dosage of $\mathrm{FHC}(1: 2)$ was $91.0 \mathrm{mg}$ $\mathrm{L}^{-1}$, the removal rate of $\mathrm{Se}(\mathrm{Iv})$ was $\approx 90 \%$. However, when the dosage of $\operatorname{FHC}(1: 2)$ was $>91.0 \mathrm{mg} \mathrm{L}^{-1}$, the increase in the Se(Iv) removal rate was not obvious. Agglomeration may be the more possible reason according to the scanning electron micrograph shown in Fig. 6.

\subsection{Effect of the $[\mathrm{Fe}(\mathrm{II})] /\left[\mathrm{OH}^{-}\right]$ratio}

Min et al. ${ }^{32}$ discovered that GRs have an LDH structure with a high anion exchange capacity according to their study on the

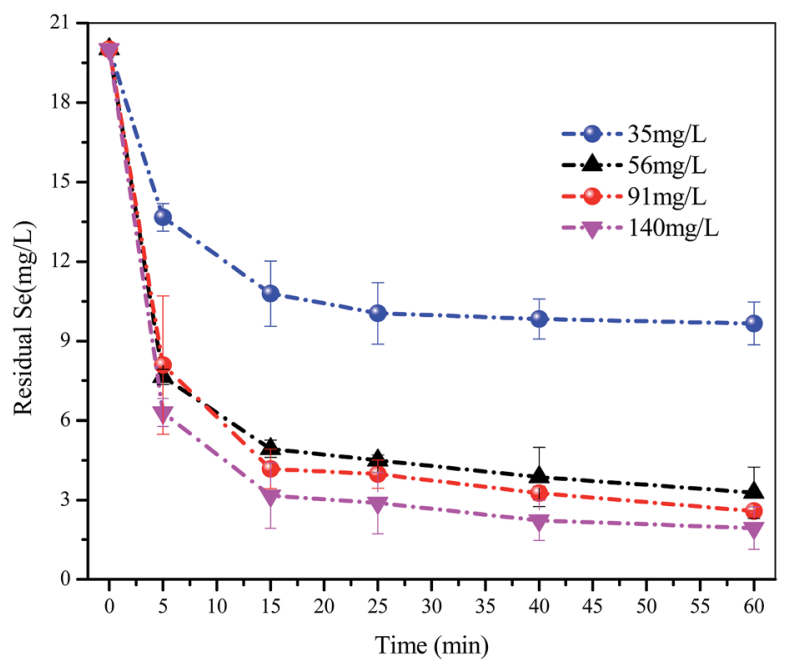

Fig. 3 The selenite solutions $\left(80 \mathrm{~mL}\right.$ and $\left.20 \mathrm{mg} \mathrm{L}^{-1}\right)$ and different adsorbent dosages (35.0, 56.0, 91.0 and $140.0 \mathrm{mg} \mathrm{L}^{-1}$ ) were mixed in separate batch bottles with a reaction time $=1 \mathrm{~h}$. sorption of iodine and Se onto GRs. Structural Fe(II) with polyhydroxyl conjoined with ferrous ions is similar to GRs and is bound up with mole ratios of $\left[\mathrm{Fe}^{2+}\right]$ to $\left[\mathrm{OH}^{-}\right]$. The effect of various mole ratios of $\left[\mathrm{Fe}^{2+}\right]$ to $\left[\mathrm{OH}^{-}\right]$was studied for the reactive properties of FHC structures. As shown in Fig. 4, the removal efficiencies of $\mathrm{SeO}_{3}{ }^{2-}$ with $\operatorname{FHC}(1: 1)$ and $\operatorname{FHC}(1: 2)$ were higher than those of $\operatorname{FHC}(1: 3)$ and $\operatorname{FHC}(1: 4)$. The solution $\mathrm{pH}$ value before and after the reaction is labeled in Table 2 . FHC with various ratios of $\left[\mathrm{Fe}^{2+}\right]$ to $\left[\mathrm{OH}^{-}\right]$caused changes in the solution pH. FHC(1:3) or $\operatorname{FHC}(1: 4)$ could increase the solution $\mathrm{pH}$ to $\geq 11.5$ and hindered the removal of $\mathrm{SeO}_{3}{ }^{2-}$. Possible causes may be the competition relationship between $\mathrm{OH}^{-}$and $\mathrm{Se}(\mathrm{Iv})$. Also, at higher $\mathrm{pH}$, the positive charge on $\mathrm{Fe}(\mathrm{II})$ hydroxides decreased and lower attraction to negative ions led to a decrease in removal rate. At lower $\mathrm{pH}$, a greater positive charge could accumulate on $\operatorname{FHC}(2: 1)$ but, with a decrease in $\mathrm{pH}$, the layered structure of FHC could be undermined and structural $\mathrm{Fe}(\mathrm{II})$ transformed into free ferrous, leading to lower selenite removal. For example, research on reductive transformation of reactive black 5 by FHCs showed that structural Fe(II) became free ferrous at $\mathrm{pH} 2$ and reductive removal ability significantly decreased. ${ }^{16}$ These results were consistent with the experiments by Hana et $a .^{25}$ Another reason may be that redundant $\mathrm{OH}^{-}$is unfavorable for FHC structural stability. The third reason might be that the mixed $\mathrm{pH}$ affected the forms of $\mathrm{Fe}(\mathrm{II})$ present. Judging from Fig. S1 (ESI $\dagger$ ) and Table 2, $\mathrm{Fe}^{2+}$ was the main form

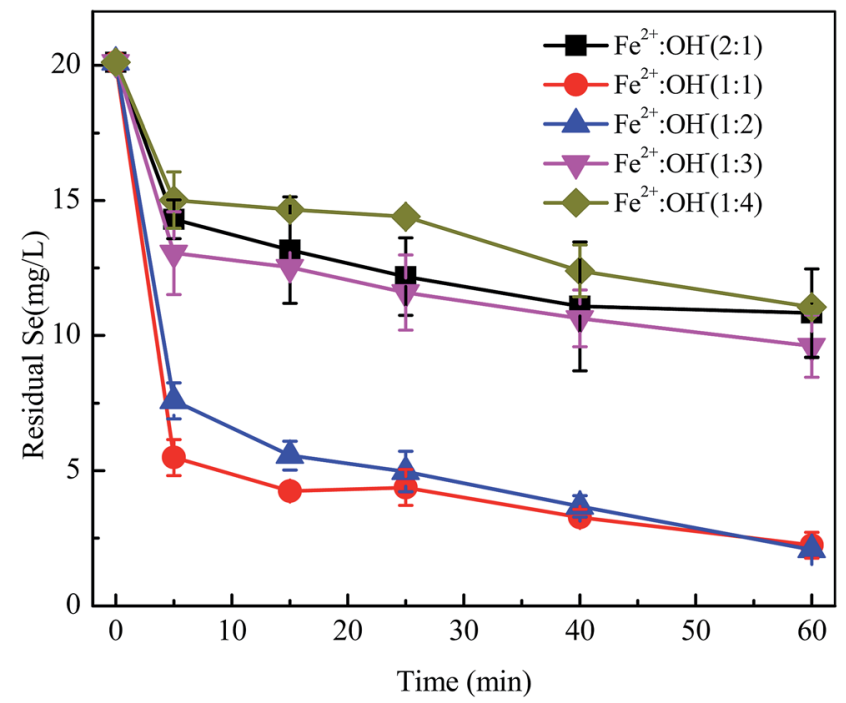

Fig. 4 Various $[\mathrm{Fe}(॥)] /\left[\mathrm{OH}^{-}\right]$ratios were mixed in batch bottles, initial $[\mathrm{Se}(\mathrm{Iv})]=20.0 \mathrm{mg} \mathrm{L}^{-1}, \mathrm{FHC}$ dosage $=114.0 \mathrm{mg} \mathrm{L}^{-1}$, and reaction time $=$ $1 \mathrm{~h}$. 
Table $2 \mathrm{pH}$ value of aqueous solution before and after the reaction

\begin{tabular}{|c|c|c|c|c|c|}
\hline$[\mathrm{Fe}(\mathrm{II})] /\left[\mathrm{OH}^{-}\right]$ & $\operatorname{FHC}(2: 1)$ & $\operatorname{FHC}(1: 1)$ & $\mathrm{FHC}(1: 2)$ & $\mathrm{FHC}(1: 3)$ & $\operatorname{FHC}(1: 4)$ \\
\hline Initial pH & 7.65 & 7.82 & 10.20 & 11.58 & 11.85 \\
\hline Reaction $\mathrm{pH}$ & 6.75 & 6.93 & 10.58 & 11.68 & 11.90 \\
\hline
\end{tabular}

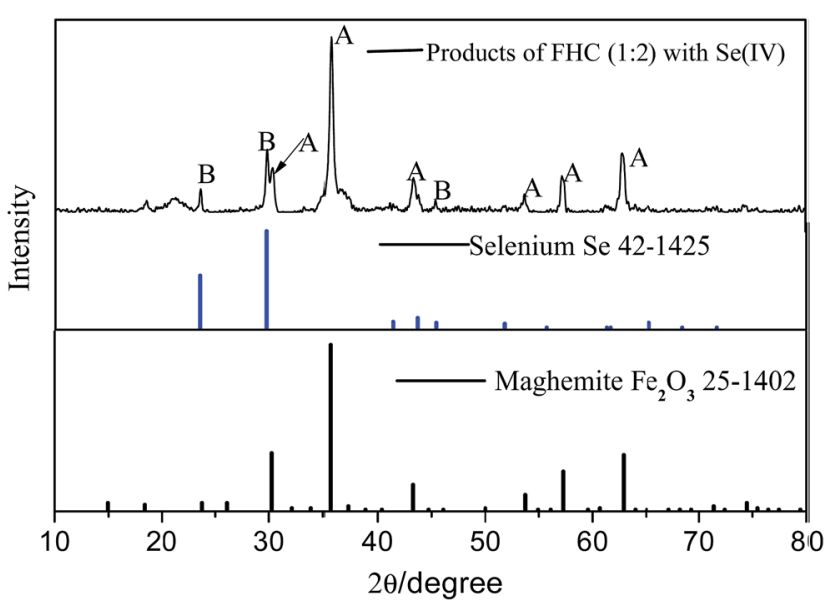

Fig. 5 XRD analyses of reacted $\mathrm{FHC}(1: 2)$ with $\mathrm{Se}(\mathrm{IV})$.

present for $\mathrm{FHC}(2: 1)$ and $\mathrm{FHC}(1: 1), \mathrm{FeOH}^{+}$was the preponderant form for $\mathrm{FHC}(1: 2)$, and $\mathrm{Fe}(\mathrm{OH})_{3}{ }^{-}$was the major form for $\operatorname{FHC}(1: 3)$ and $\operatorname{FHC}(1: 4)$. Therefore, $\operatorname{FHC}(2: 1), \operatorname{FHC}(1: 1)$ and $\mathrm{FHC}(1: 2)$ were $\mathrm{pH}$-dependent positive charge surfaces and $\operatorname{FHC}(1: 3)$ and $\mathrm{FHC}(1: 4)$ were $\mathrm{pH}-d e p e n d e n t$ negative charge surfaces. A positive charge is better for selenite adsorption and then reduction, whereas electrostatic repulsion of a negative charge antagonizes selenite sequestration. There was a special phenomenon in the solution $\mathrm{pH}$ value before and after the reaction. When $\operatorname{FHC}(2: 1)$ and $\operatorname{FHC}(1: 1)$ were used as adsorbents, the $\mathrm{pH}$ mainly decreased. When FHC(1:2)-FHC(1:4) were used, the $\mathrm{pH}$ was increased or changed slightly. This phenomenon is possible due to a deviation in $\mathrm{pH}$ determination. The authentic interpretation of Se(rv) removed by structural Fe(II) should be obtained in further investigations at the molecular level using spectroscopic methods such as XPS.

\subsection{Solid-phase analyses}

XRD diffraction patterns showed products of $\operatorname{FHC}(1: 2)$ with Se(rv) (Fig. 5). Maghemite (PDF: 25-1402) is consistent with the products of GRs with Se(Iv).$^{19}$ The intermediate products of GRs were formed in the reaction, which was followed by the adsorption of Se(rv) onto them in a subsequent process. In addition, characteristic strong reflections at $2 \theta=23.5^{\circ}, 29.7^{\circ}$ and $43.6^{\circ}$ were detected, which were taken to be for Se (PDF: $42-$ 1425). The result showed Se(Iv) was reduced to crystalline $\mathrm{Se}(0)$ in the reaction.

Fig. 6 displays the scanning electron microscopy (SEM) images of fresh FHC (A) and reacted FHC (B and C). Many intervals were observed in the image of fresh FHC, and it was obvious that the reacted FHC formed an agglomeration, and FHC $(1: 4)$ granules apparently grew larger, which was a possible reason for the lower removal rate of Se(Iv). According to energy dispersive X-ray spectrometry (EDS) (Fig. 7 ), the level of solid Se on FHC(1:1) or FHC(1:2) was obviously higher than that for $\mathrm{FHC}(1: 4)$ in the final products, which could also demonstrate that the removal capacity of the former was higher than that for the latter.

Structural $\mathrm{Fe}(\mathrm{II})$ exists as a poly-hydroxyl conjoined with $\mathrm{Fe}(\mathrm{II})$, whose structure is similar to GRs, and the removal mechanism for this heavy metal is also similar. ${ }^{33}$ Some studies have demonstrated ion exchange during processing, making it

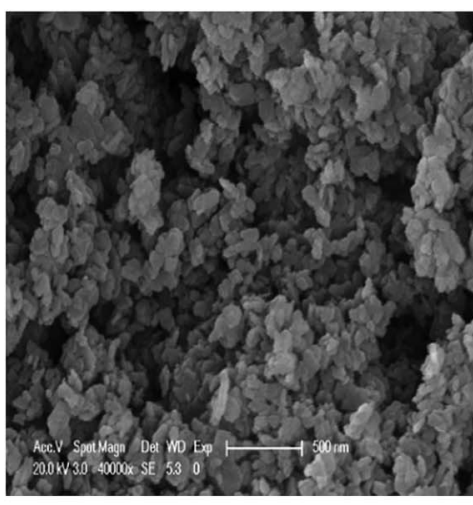

FHC (1:1)

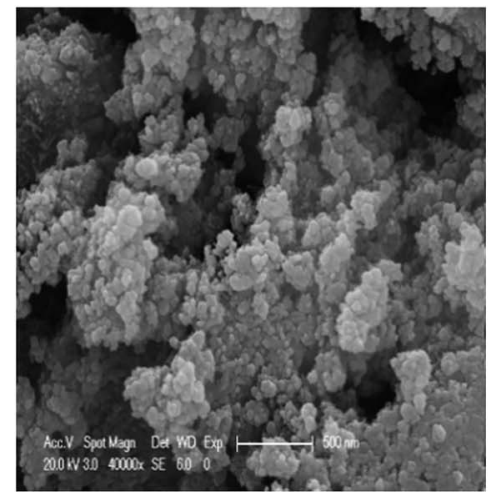

FHC (1:1) +Se (IV)

B

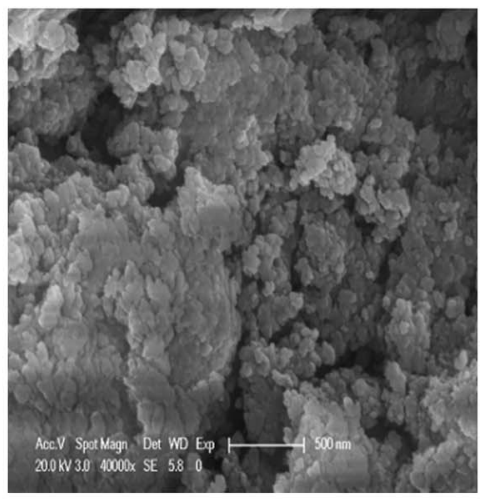

FHC (1:4) +Se (IV)

C

Fig. 6 SEM images of fresh $\operatorname{FHC}(1: 1)$ and reacted $\operatorname{FHC}(1: 1)$ and $\operatorname{FHC}(1: 4)$. 


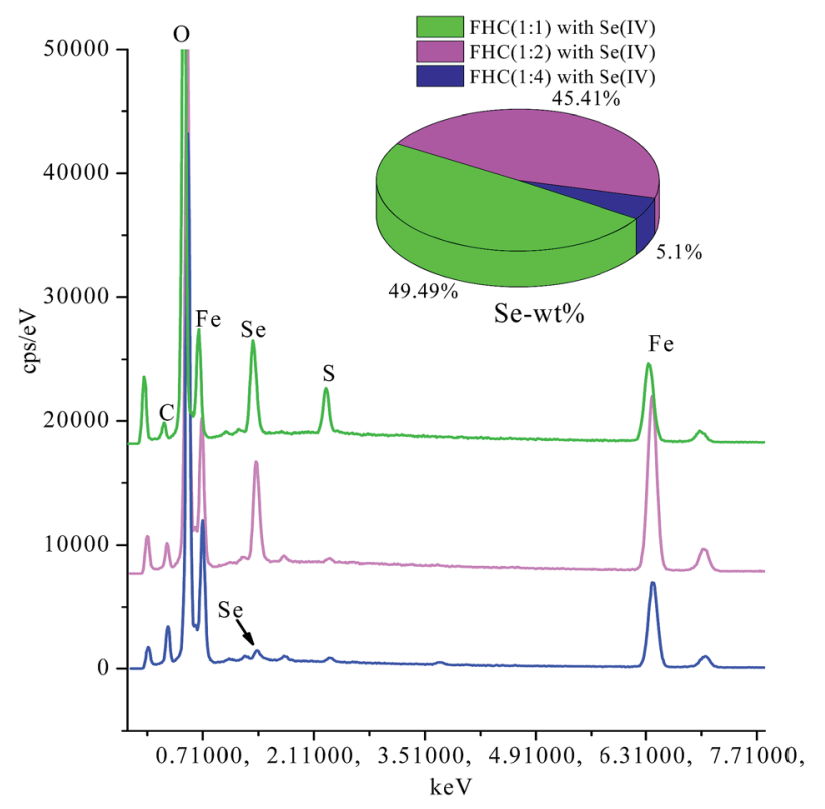

Fig. 7 EDS analyses of FHC with Se(Iv).

necessary for future study on structural $\mathrm{Fe}(\mathrm{II})$ in solid products. Fig. 8 shows the O1s XPS spectra of $\operatorname{FHC}(2: 1), \operatorname{FHC}(1: 1)$, $\mathrm{FHC}(1: 2), \mathrm{FHC}(1: 3)$ and $\mathrm{FHC}(1: 4)$ products that were reacted with $\mathrm{Se}(\mathrm{Iv})$. The O1s spectra were fitted with three components at 529.0-529.7 eV, 530.2-530.7 eV, and 531.1-531.7 eV, which corresponded to the oxygen ion $\left(\mathrm{O}^{2-}\right)$, structural hydroxide $\left(\mathrm{OH}^{-}\right)$, and adsorbed water molecule $\left(\mathrm{H}_{2} \mathrm{O}\right)$, respectively. ${ }^{34}$ The structural hydroxide originated from hydroxyl ions in solution or dissociation of absorbed water molecules and, when present, atmospheric $\mathrm{O}_{2}$ could originate from the combination of a proton $\left(\mathrm{H}^{+}\right)$and $\mathrm{O}^{2-}$, which was produced by the reduction of
$\mathrm{O}_{2} \cdot{ }^{35}$ Although all experiments were conducted in an anaerobic chamber, the residual $\mathrm{O}_{2}$ on the solution surface could never be completely expelled, and the solid samples were exposed to air when transferred for XPS analyses. Fig. 8 shows that the peak area of $\mathrm{O}^{2-}, \mathrm{H}_{2} \mathrm{O}$ and $\mathrm{OH}^{-}$changed with the ratios of $([\mathrm{Fe}(\mathrm{II})] /$ $\left.\left[\mathrm{OH}^{-}\right]\right)$. Due to the effect of the $[\mathrm{Fe}(\mathrm{II})] /\left[\mathrm{OH}^{-}\right]$ratio, the peak area of structural hydroxide $\left[\mathrm{OH}^{-}\right]$was moderate and the removal rate was better. When the $[\mathrm{Fe}(\mathrm{II})] /\left[\mathrm{OH}^{-}\right]$ratio was $1: 4$, however, the affinity of residual $\mathrm{OH}^{-}$was superior to $\mathrm{Se}(\mathrm{Iv})$ and hindered the removal of Se(rv).

There are some limitations in the analyses of XPS spectra that contain Fe and Se due to the interference between Fe3p and Se3d. Fortunately, because there was no overlap in the binding energy between $\mathrm{Se}(\mathrm{Iv}) 3 \mathrm{~d}$ and Fe3p, the changes in Se(Iv) in the solid stage could be observed. Based on the National Institute of Standards and Technology binding energy database, Fe3p spectra of structural $\mathrm{Fe}(\mathrm{II})$ are at $55.9 \mathrm{eV}$, Se3d spectra of Se(Iv) are at $59.1 \mathrm{eV}$, and spectra peaks of $\mathrm{Se}(0)$ are at $54.6-55.9 \mathrm{eV}^{36}$ Obviously, it was difficult to analyze the existence of $\mathrm{Fe}$ and $\mathrm{Se}(0)$ on the solid surface from XPS spectra. According to Fig. 9a, Fe3p spectra of structural Fe(II) without Se were present at 55.6-57.6 eV, which overlapped with the Se3d peaks 54.8$57.8 \mathrm{eV}$ in Fig. 9b-d. As shown in Fig. 9b-d, the peak intensity was obviously stronger in Fig. 9b and the contents of Se(rv) in the solid state were ranked in the following order: $b>c>d$. Therefore, Se(Iv) removal by structural Fe(II) changed with various $[\mathrm{Fe}(\mathrm{II})] /\left[\mathrm{OH}^{-}\right]$ratios.

With use of a sequential extraction procedure, Se in sediments was classified into the following five groups: watersoluble, exchangeable, elemental $\mathrm{Se}$, oxides-containing $\mathrm{Fe}$ state, and selenide. Fig. 10A-C, respectively, show $\operatorname{FHC}(2: 1)$, $\operatorname{FHC}(1: 1)$ as well as $\operatorname{FHC}(1: 4)$ reacted with $\operatorname{Se}(\mathrm{rv})$. The percentage content of water-soluble and oxide-containing Festate Se might be neglected. $\mathrm{Se}(0)$ was the main reduction
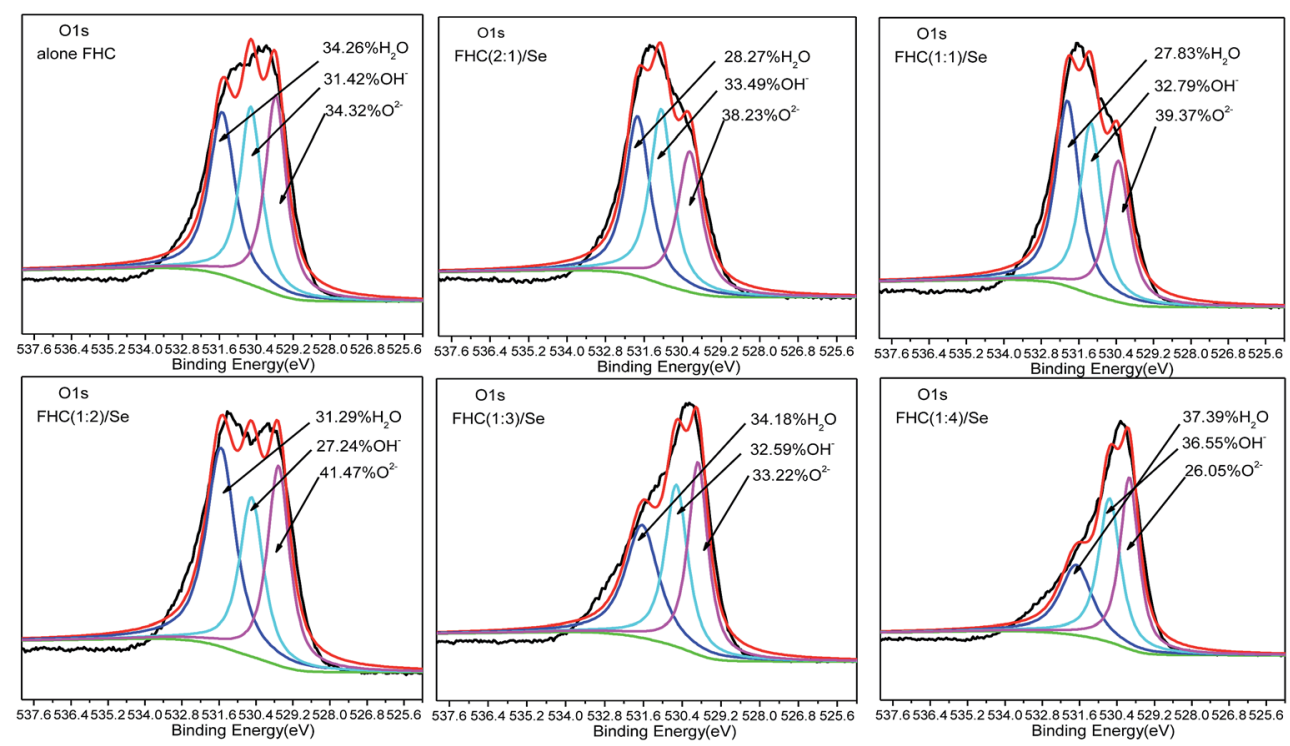

Fig. 8 O1s XPS spectra of $\mathrm{FHC}$ of different $[\mathrm{Fe}(\mathrm{II})] /\left[\mathrm{OH}^{-}\right]$ratios on the removal of Se(Iv). Initial $[\mathrm{Se}(\mathrm{Iv})]=20.0 \mathrm{mg} \mathrm{L}^{-1}, \mathrm{FHC} \mathrm{dosage}=114.0 \mathrm{mg} \mathrm{L}^{-1}$, and reaction time $=1 \mathrm{~h}$. 

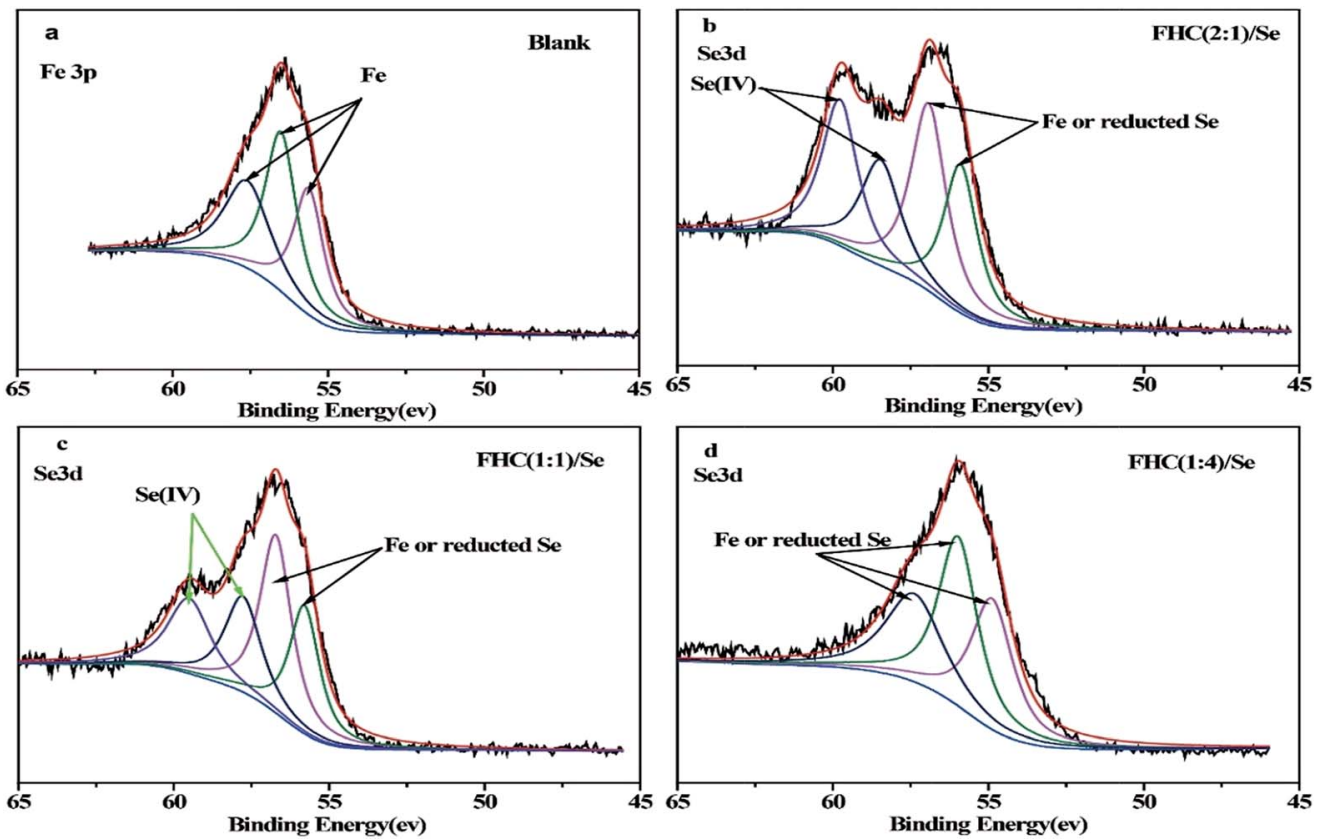

Fig. $9 \mathrm{Se} 3 \mathrm{~d}$ XPS spectra of $\mathrm{FHC}$ of different $[\mathrm{Fe}(\mathrm{II})] /\left[\mathrm{OH}^{-}\right]$ratios on the removal of Se(Iv). Initial $[\mathrm{Se}(\mathrm{IV})]=20.0 \mathrm{mg} \mathrm{L}^{-1}, \mathrm{FHC} \mathrm{dosage}=114.0 \mathrm{mg} \mathrm{L}^{-1}$, reaction time $=1 \mathrm{~h}$.

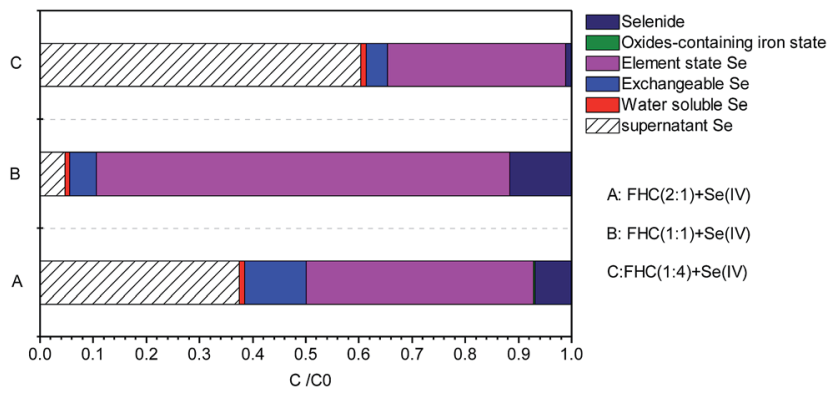

Fig. 10 Various $[\mathrm{Fe}(I)] /\left[\mathrm{OH}^{-}\right]$ratios with Se(Iv) were sequentially extracted; initial $[\mathrm{Se}(\mathrm{IV})]=20.0 \mathrm{mg} \mathrm{L}^{-1}$ and $\mathrm{FHC}$ dosage $=114.0 \mathrm{mg} \mathrm{L}^{-1}$

product and accounted for $77 \%$ of the five groups when FHC $(1: 1)$ was reacted with Se(Iv). The presence of exchangeable Se indicated that FHC had the function of flocculation adsorption. The percentage content of exchangeable Se on $\operatorname{FHC}(2: 1)$ was obviously higher than that for $\operatorname{FHC}(1: 4)$ or FHC $(1: 1)$. This conclusion was consistent with XPS spectra analyses of Se. The results of sequential extraction treatment indicated that reduction immobilization was the principal approach for selenite removal.

The bidentate inner-sphere surface complexes formed on the structural Fe(II) surface was consistent with previous studies..$^{37,38}$ Shrimpton et al. studied Se(vi) reduction by zerovalent Fe and found Se(Iv) could be reduced to $\mathrm{Se}(0)$. Under high $\mathrm{pH}$ conditions, the main precipitation products were iron selenides. However, at low pH, neither $\mathrm{FeSe}_{2}$ nor FeSe was observed in that study ${ }^{39}$ As the reaction time progressed, structural Fe(II) could be gradually oxidized to GRs. Afterwards, Se(Iv) was mainly reduced to $\mathrm{Se}(0)$ and then participated in interlayer ion exchange, which could contribute to the removal capacity of structural $\mathrm{Fe}$ (II) being better than GRs. The reducibility of structural $\mathrm{Fe}$ (II) was obviously stronger than that of GRs, which was different from many other removal mechanisms., ${ }^{9,18,40-42}$ $\mathrm{Se}(\mathrm{Iv})$ was either absorbed on the surface of structural Fe(II) mineral and reduced to $\mathrm{Se}(0)$ or ion-exchange between $\mathrm{Se}(\mathrm{Iv})$ and other anions occurred.

\section{Conclusions}

FHCs were synthesized and employed to remove selenite. The $\mathrm{Se}(\mathrm{Iv})$ removal isotherm was adequately described by the BET isotherm, and the calculated maximum removal capacity of $\mathrm{Se}(\mathrm{Iv})$ was $256.41 \mathrm{mg} \mathrm{g}^{-1}$. The corresponding fitting result was more coincident with the pseudo-second order kinetic model and the reaction rate constant $(k)$ was $1.05 \times 10^{-3} \mathrm{mg} \mathrm{g}^{-1}$ $\min ^{-1}$. When the $\operatorname{FHC}(1: 2)$ dosage was $91.0 \mathrm{mg} \mathrm{L}^{-1}$, the removal rate was $\approx 90 \%$. The amount of solid Se on $\operatorname{FHC}(1: 1)$ or $\operatorname{FHC}(1: 2)$ was obviously more than $\operatorname{FHC}(1: 4)$ in the final products, which could also demonstrate that the removal capacity of the former was higher than that of the latter. XRD diffraction patterns showed that structural Fe(II) was translated into maghemite and $\mathrm{Se}(\mathrm{Iv})$ was reduced to crystalline $\mathrm{Se}(0)$ by $\mathrm{FHC}(1: 2)$. XPS spectra indicated that the mechanism of Se(rv) removal by $\mathrm{FHC}(1: 1)$ involved the combined effects of adsorption and reduction, and $\mathrm{Se}(\mathrm{Iv})$ removal by $\mathrm{FHC}(1: 4)$ principally involved reduction. Se(Iv) removal by structural Fe(II) changed with various ratios of $[\mathrm{Fe}(\mathrm{II})] /\left[\mathrm{OH}^{-}\right]$. With use of a sequential extraction procedure, Se in sediments was classified into five groups: water-soluble, exchangeable, elemental Se, oxide-containing Fe state, and selenide. Crystalline $\mathrm{Se}(0)$ was the main reduction product. The higher uptake of selenite 
indicated that structural $\mathrm{Fe}(\mathrm{II})$ was a lower-cost, effective material for selenite removal.

\section{Acknowledgements}

This study was financially supported by the Natural Science Foundation of China (Grant No. 51278356, 41572211).

\section{Notes and references}

1 F. Chen, P. C. Burns and R. C. Ewing, J. Nucl. Mater., 1999, 275, 81-94.

2 E. Breynaert, C. Bruggeman and A. Maes, Environ. Sci. Technol., 2008, 42, 3595-3601.

3 D. L. Hatfield, Selenium: its molecular biology and role in human health, Springer, 2006.

4 J. A. Plant, D. G. Kinniburgh, P. L. Smedley, F. M. Fordyce and B. A. Klinck, Treatise Geochem., 2003, 9, 17-66.

5 A. D. Lemly, Ecotoxicol. Environ. Saf., 2004, 59, 44-56.

6 L. H. E. Winkel, C. A. Johnson, M. Lenz, T. Grundl, O. X. Leupin, M. Amini and L. Charlet, Environ. Sci. Technol., 2012, 46, 571-579.

7 H. Wen and J. Carignan, Geochim. Cosmochim. Acta, 2011, 75, 1411-1427.

8 J. S. Cleverley and E. N. Bastrakov, Comput. Geosci., 2005, 31, 756-767.

9 R. L. D. A. Loyo, S. I. Nikitenko, A. C. Scheinost and M. Simonoff, Environ. Sci. Technol., 2008, 42, 2451-2456.

10 A. C. Scheinost and L. Charlet, Environ. Sci. Technol., 2008, 42, 1984-1989.

11 A. C. Scheinost, R. Kirsch, D. Banerjee, A. FernandezMartinez, H. Zaenker, H. Funke and L. Charlet, J. Contam. Hydrol., 2008, 102, 228-245.

12 A. Naveau, F. Monteil-Rivera, E. Guillon and J. Dumonceau, Environ. Sci. Technol., 2007, 41, 5376-5382.

13 T. Missana, U. Alonso, A. C. Scheinost, N. Granizo and M. García-Gutiérrez, J. Cont. Educ. Nurs., 2009, 73, 62056217.

14 L. P. Liang, W. Yang, X. H. Guan, J. Li, Z. Xu, J. Wu, Y. Huang and X. Zhang, Water Res., 2013, 47, 5846-5855.

15 L. Ling, B. Pan and W. X. Zhang, Water Res., 2015, 71, 274281.

16 W. U. Deli, Y. Feng and M. A. Luming, J. Huazhong Univ. Sci. Technol., Med. Sci., 2011, 39, 1657-1662.

17 S. Chakraborty, F. Bardelli and L. Charlet, Environ. Sci. Technol., 2010, 44, 1288-1294.

18 N. Chubar, V. Gerda and M. Szlachta, Environ. Sci. Technol., 2014, 48, 13376-13383.
19 S. C. B. Myneni and T. K. Tokunaga, Science, 1997, 278, 11061109.

20 D. L. Wu, Q. M. Wang, Y. Feng and L. M. Ma, Adv. Mater. Res., 2012, 518-523, 1737-1743.

21 B. B. Shao, Y. Y. Guan and D. L. Wu, SICHUAN Environment, 2016, 5, 13-19.

22 S. W. Wu and Q Chi, Soils, 2004, 36, 91-92.

23 B. A. Manning and R. G. Burau, Environ. Sci. Technol., 1995, 29, 2639-2646.

24 M. A. Wilson, R. Burt, W. C. Lynn and L. C. Klameth, Commun. Soil Sci. Plant Anal., 1997, 28, 407-426.

25 S. H. Dong, B. Batchelor and A. Abdel-Wahab, J. Hazard. Mater., 2011, 186, 451-457.

26 L. Liang, X. Jiang, W. Yang, Y. Huang, X. Guan and L. Li, Desalin. Water Treat., 2015, 53, 1-9.

27 M. Szlachta, V. Gerda and N. Chubar, J. Colloid Interface Sci., 2012, 365, 213-221.

28 Y. T. Chan, H. K. Wen, T. Y. Chen and K. W. Ming, Water Res., 2009, 43, 4412-4420.

29 Z. P. Wen, C. Dai, Y. Zhu and Y. L. Zhang, $R S C A d v .$, 2015, 5, 4058-4068.

30 Z. Wen, Y. Zhang and C. Dai, Colloids Surf., A, 2014, 457, 433440.

31 N. Chubar and V. Gerda, Environ. Sci. Technol., 2014, 48, 13376-13383.

32 J. H. Min, M. H. Baik, J. K. Lee and J. T. Jeong, China Nuclear Technology Report, 2013, 1, 56-72.

33 B. Verbinnen, C. Block, P. Lievens, A. V. Brecht and C. Vandecasteele, Waste Biomass Valorization, 2013, 4, 635-645.

34 S. W. Knipe, J. R. Mycroft, A. R. Pratt, H. W. Nesbitt and G. M. Bancroff, Geochim. Cosmochim. Acta, 1995, 59, 10791090.

35 H. W. Nesbitt and I. J. Muir, Geochim. Cosmochim. Acta, 1994, 58, 4667-4679.

36 J. R. Rumble, D. M. Bickham and C. J. Powell, Surf. Interface Anal., 1992, 19, 241-246.

37 H. Wijnja and C. P. Schulthess, J. Colloid Interface Sci., 2000, 229, 286-297.

38 A. Fernández-Martínez and L. Charlet, Rev. Environ. Sci. Bio/ Technol., 2009, 8, 81-110.

39 H. K. Shrimpton, D. W. Blowes and C. J. Ptacek, Environ. Sci. Technol., 2015, 49, 11688-11696.

40 J. T. Olegario, N. Yee, M. Miller, J. Sczepaniak and B. Manning, J. Nanopart. Res., 2010, 12, 2057-2068.

41 L. Liang, X. Guan, Z. Shi, J. Li, Y. Wu and P. G. Tratnyek, Environ. Sci. Technol., 2014, 48, 6326-6334.

42 A. E. Schellenger and P. Laresecasanova, Environ. Sci. Technol., 2013, 47, 6254-6262. 